\title{
Infrared reflection absorption study of water interaction with H-terminated $\mathrm{Si}(\mathbf{1 0 0})$ surfaces
}

\author{
G RANGA RAO \\ Department of Chemistry, Indian Institute of Technology Madras, Chennai 600 036, India
}

MS received 16 July 2004

\begin{abstract}
Water adsorption on clean and hydrogenated $\mathrm{Si}(100)$ surfaces was studied under ultra high vacuum conditions using surface infrared spectroscopy. The study shows that $\mathrm{H}-\mathrm{Si}-\mathrm{Si}-\mathrm{OH}$ and $\mathrm{SiH}_{2}$ species are formed on $\mathrm{Si}(100)-(2 \times 1)$ and $\mathrm{Si}(100)-(2 \times 1)-\mathrm{H}$ surfaces, respectively. The reactivity behaviour of $\mathrm{Si}(100)-$ $(3 \times 1)-\mathrm{H}$ and $\mathrm{Si}(100)-(1 \times 1)-\mathrm{H}$ is similar, both stabilizing oxygen inserted silicon dihydrides.
\end{abstract}

Keywords. IR; $\mathrm{Si}(100)$; water adsorption.

\section{Introduction}

Chemistry of silicon surfaces and interfaces is widely explored due to the importance of silicon in semiconductor industry. Interaction of variety of small and large adsorbate molecules with silicon surfaces has been the subject of recent interest aimed at tuning the surface molecular properties and the development of silicon-based biosensors and membrane chips (Waltenburg and Yates 1995; Hamers et al 2000; Reddy et al 2001; Ashkenasy et al 2002; Buriak 2002). The adsorption of water on silicon single-crystal surfaces is another area of interest in silicon surface chemistry to reveal the atomic details of the surface oxidation mechanisms for controlling the $\mathrm{SiO}_{2}$ gate oxide thickness to $\sim 2 \mathrm{~nm}$ in microelectronics (Gurevich et al 1998; Chabal and Raghavachari 2002). The creation and selective removal of thin $\mathrm{SiO}_{2}$ layers are thus important processes in semiconductor device fabrication. The stable ultra thin surface $\mathrm{SiO}_{2}$ layers are usually formed using water as an oxidant and etched off by weak acid, HF, which can remove $\mathrm{SiO}_{2}$ layers at the rate of $100 \mathrm{~nm}$ per min (Liu et al 1992; Jones et al 1995). In order to understand the chemical oxidation process by water adsorption, the $\mathrm{Si}(100)$ surfaces have been investigated under ultra high vacuum conditions by high resolution electron energy loss spectroscopy (Ibach et al 1982; Ikeda et al 1995; Bitzera et al 1997) and surface infrared spectroscopy (Struck et al 1997; Weldon et al 1997, 2000; Chabal and Raghavachari 2002; Wang et al 2002, 2004; Ranga Rao et al 2004).

Silicon crystal has diamond lattice structure with $s p^{3}$ hybridization. The surfaces of silicon crystals contain dangling bonds due to the cleavage of covalent bonds. The dangling bonds at the surface are responsible for the reconstruction of $\mathrm{Si}(100)$ leading to the formation of $\mathrm{Si}(100)$ $(2 \times 1)$ structure consisting of surface $\mathrm{Si}=\mathrm{Si}$ dimers with a $\sigma$ and a $\pi$ bond. Adsorption of atomic hydrogen on
Si(100) surfaces at different temperatures under ultra high vacuum conditions gives rise to H-terminated $(2 \times 1)$ coupled monohydride $(\mathrm{CM})(\mathrm{H}-\mathrm{Si}-\mathrm{Si}-\mathrm{H}),(1 \times 1)$ isolated dihydride (ID) $(\mathrm{H}-\mathrm{Si}-\mathrm{H})$, and $(3 \times 1)$ coupled monohydride and dihydride structures. The $\mathrm{Si}(100)-(2 \times 1)-\mathrm{H}$ structure which forms after saturation exposure of atomic $\mathrm{H}$ at the surface temperature of about $600-650 \mathrm{~K}$ exhibits characteristic $\mathrm{v}(\mathrm{Si}-\mathrm{H})$ modes at $2099\left(A_{1}\right.$ symmetry $)$ and $2088 \mathrm{~cm}^{-1}\left(B_{1}\right.$ symmetry) (Tautz and Schaefer 1998). The Si(100)-(3 $\times$ 1) $-\mathrm{H}$ structure consisting of coupled monohydride and dihydride species can be produced by exposing $\mathrm{Si}(100)-$ $(2 \times 1)$ surface to saturation atomic $\mathrm{H}$ at $400 \mathrm{~K}$ (Weldon et al 2000; Noda and Urisu 2000). The Si(100) $-(1 \times 1)-\mathrm{H}$ structure is prepared by saturation exposure of atomic $\mathrm{H}$ to $\mathrm{Si}(100)-(2 \times 1)$ at $300 \mathrm{~K}$. The $(1 \times 1)-\mathrm{H}$ phase is reported to be a disordered mixture of coupled monohydride, di- and tri-hydrides $\left(\mathrm{SiH}_{3}\right)$ (Waltenburg and Yates 1995). Both $(3 \times 1)-\mathrm{H}$ and $(1 \times 1)-\mathrm{H}$ structures show 902 and $913 \mathrm{~cm}^{-1}$ peaks in the $\mathrm{Si}-\mathrm{H}$ bending region due to the isolated (ID) and adjacent (AD) $\mathrm{SiH}_{2}$, respectively. In the $\mathrm{Si}-\mathrm{H}$ stretching region, the isolated and adjacent $\mathrm{SiH}_{2}$ species are identified with $2090 \mathrm{~cm}^{-1}$ and $2107 \mathrm{~cm}^{-1}$, respectively (Noda and Urisu 2000).

The vibrational spectroscopic investigations of water adsorption on $\mathrm{Si}(100)-(2 \times 1)$ surfaces have shown the formation of $\mathrm{H}-\mathrm{Si}-\mathrm{Si}-\mathrm{OH}$ species on each $\mathrm{Si}=\mathrm{Si}$ dimer (Ibach et al 1982; Struck et al 1997; Weldon et al 2000; Wang et al 2002). Upon thermal annealing the decomposition of surface hydroxyl groups and the incorporation of oxygen atoms into the $\mathrm{Si}$ dimer-bonds as well as $\mathrm{Si}$ back-bonds occur in the top layers of $\mathrm{Si}$ until the hydrogen desorption temperatures above $650 \mathrm{~K}$. The surface IR spectroscopy has provided impetus to study the mechanistic aspects of oxygen atom insertion into surface $\mathrm{Si}$ layers (Mawhinney et al 1997; Ogata et al 1995; Gurevich et al 1998; Chabal and Raghavachari 2002; Ranga Rao et al 2004; Wang et al 2004). This article reports the 
interaction of water with H-terminated $\mathrm{Si}(100)$ surfaces under UHV conditions employing surface sensitive infrared reflection method. The study indicates that H-terminated $\mathrm{Si}(100)$ surfaces are less reactive due to the nonavailability of dangling bonds compared to the bare $\mathrm{Si}(100)$ surfaces and tend to form oxygen inserted surface silicon dihydrides.

\section{Experimental}

The infrared reflection absorption spectroscopy (IRRAS) experiments were carried out using an ultrahigh-vacuum (UHV) reaction chamber equipped with IRRAS optical system and reflective high-energy electron diffraction (RHEED) facility (Wang et al 2002; Ranga Rao et al 2004). The base pressure of the experimental chamber was maintained at $<2 \times 10^{-10}$ Torr by pumping with a turbomolecular pump (500 $\mathrm{L} \mathrm{s}^{-1}$ ). The optical path of the IRRAS system was continuously purged with pure $\mathrm{N}_{2}$ gas. A $p$ polarized IR beam from a Fourier transform spectrometer (JEOL JIR 7000) was selected by a wire grid polarizer using KRS-5 infrared transmissive lens and directed into the reaction chamber through a $\mathrm{ZnSe}$ view port at an incident angle of $85^{\circ}$ with respect to the silicon surface normal. The reflected IR beam was detected by liquid nitrogen cooled HgCdTe (MCT) detector outside the UHV chamber.

The $\mathrm{CoSi}_{2}$ burried metal layer (BML) $\mathrm{Si}(100)$ wafer was employed in this study. The $100 \mathrm{~nm}$ thick $\mathrm{CoSi}_{2}$ layer acts as an IR reflector and the vibrational components perpendicular to the sample surface can be detected by the IR external reflection optical geometry without the interference of Si phonons (Ehrley et al 1991; Struck et al 1997). A piece of silicon wafer was cut and cleaned by wet chemical methods (Liu et al 1992). The sample cleaning procedure involved degreasing in acetone and methanol solutions, treatment with $\mathrm{HF}$ solution and finally with $\mathrm{HCl}+\mathrm{H}_{2} \mathrm{O}_{2}+\mathrm{H}_{2} \mathrm{O}$ solution before transferring into the experimental chamber. The BML-Si(100) sample was then degassed slowly up to $600 \mathrm{~K}$ keeping the chamber pressure $<5 \times 10^{-9}$ Torr followed by a flash to $1200 \mathrm{~K}$ to remove the surface oxide. A silicon epitaxial layer of about $50 \mathrm{~nm}$ thick was grown over the rough BML-Si(100) surface using $\mathrm{Si}_{2} \mathrm{H}_{6}$ gas at $975 \mathrm{~K}$. The deposition of $50 \mathrm{~nm}$ thick silicon epitaxial film required $\mathrm{Si}_{2} \mathrm{H}_{6}$ gas exposure at $10^{-3}$ Torr for $30 \mathrm{~s}$. After epitaxy, the total thickness of the Si overlayer above the $\mathrm{CoSi}_{2}$ reflector was about $100 \mathrm{~nm}$ which was sufficient to obtain good surface IR reflection signal. The sample showed clear $\operatorname{Si}(100)-(2 \times 1)$ RHEED pattern after brief annealing (Kobayashi et al 1996). The Si(100)- $(2 \times 1)$ surface was further used to prepare H-terminated silicon surfaces.

The IRRAS measurements were carried out by accumulating 300 scans at $2 \mathrm{~cm}^{-1}$ resolution and the reported spectra are the ratio of absorption spectra for water covered Si surfaces to the D- or H-terminated Si surfaces recor- ded at the same temperature. The sample was heated by using ceramic heater (pyrolytic graphite/pyrolytic boron nitride). The sample temperature was controlled by a proportion-integral-differential (PID) controller with a WRe thermocouple attached to the rear side of the $\mathrm{Si}(100)$ substrate. The thermocouple was calibrated by an optical pyrometer (emissivity $=0.8$ for $\mathrm{Si}$ ) and the sample temperature was kept constant during the IR measurements to avoid spectral distortions.

Atomic $\mathrm{H}$ and $\mathrm{D}$ were produced at appropriate gas pressures by using incandescent tungsten filament and the typical dosing time is $20 \mathrm{~s}$. The exposures were measured in Langmuir units ( $1 \mathrm{~L}=10^{-6}$ Torr-s) from uncalibrated ion gauge readings. In this study, the procedures followed for IR measurements include thermal cleaning of the $\mathrm{Si}(100)$ BML sample up to $1200 \mathrm{~K}, 2000 \mathrm{~L}$ saturation exposure of atomic $\mathrm{H}$ or $\mathrm{D}$ at $673 \mathrm{~K}$ and allowing the samples to reach the measurement temperatures. The samples were exposed to controlled amount of water at a desired temperature. All the samples were checked for appropriate surface periodicity after hydrogen or deuterium exposures. The hydrogen covered $(2 \times 1)-\mathrm{H},(3 \times 1)-\mathrm{H}$ and $(1 \times 1)-\mathrm{H}$ surfaces were prepared by exposing clean or deuteriated $\mathrm{Si}(100)-(2 \times 1)$ surface to atomic $\mathrm{H}$ at $648 \mathrm{~K}, 400 \mathrm{~K}$ and $300 \mathrm{~K}$, respectively, under UHV conditions.

\section{Results and discussion}

The clean $\mathrm{Si}(100)-(2 \times 1)$ surface is prepared as described in the experimental section and exposed to $2000 \mathrm{~L}$ atomic deuterium at $648 \mathrm{~K}$ before cooling to $373 \mathrm{~K}$ to collect background surface infrared signal. The deuterium atoms are subsequently flashed out at $1050 \mathrm{~K}$. The clean $\mathrm{Si}(100)-(2 \times 1)$ surface is exposed to $2000 \mathrm{~L}$ atomic hydrogen at $648 \mathrm{~K}$ to obtain $\mathrm{Si}(100)-(2 \times 1)-\mathrm{H}$. These surfaces are further used for water adsorption experiments. The infrared reflection spectra of water adsorbed on bare $\mathrm{Si}(100)-(2 \times 1)$ and $\mathrm{Si}(100)-(2 \times 1)-\mathrm{H}$ surfaces at $373 \mathrm{~K}$ are shown in figure 1 . The spectra are presented as the ratios of absorption spectra of the water exposed $\mathrm{Si}(100)-(2 \times 1)$ surface to the $\mathrm{Si}(100)-(2 \times 1)-\mathrm{D}$ surface (figure $1 \mathrm{a})$ and the water exposed $\mathrm{Si}(100)-(2 \times 1)-\mathrm{H}$ surface to the $\mathrm{Si}(100)-$ $(2 \times 1)-\mathrm{H}$ surface (figure $1 \mathrm{~b})$ recorded at $373 \mathrm{~K}$. The vibrational peaks at 822,1526 and $2081 \mathrm{~cm}^{-1}$ are assigned, respectively, to the stretching modes of $\mathrm{Si}-\mathrm{OH}, \mathrm{Si}-\mathrm{D}$ and $\mathrm{Si}-\mathrm{H}$ species present on $\mathrm{Si}(100)-(2 \times 1)$ surface. The negative infrared absorption peak at $1526 \mathrm{~cm}^{-1}$ is from the deuteriated $\mathrm{Si}(100)-(2 \times 1)$ surface which was taken as infrared background. The $\mathrm{Si}-\mathrm{OH}$ and $\mathrm{Si}-\mathrm{H}$ species are formed from the dissociative adsorption of water molecule and bonded to the two $\mathrm{Si}$ atoms of the same $(2 \times 1)$ dimer unit giving rise to $\mathrm{H}-\mathrm{Si}-\mathrm{Si}-\mathrm{OH}$ surface species (Ibach et al 1982; Weldon et al 2000). At higher exposures of water the stable $\mathrm{Si}-\mathrm{H}$ and $\mathrm{Si}-\mathrm{OH}$ groups undergo considerable structural changes due to large scale decomposition of water and 
adsorbed $\mathrm{O}-\mathrm{H}$ groups generating several oxygenated surface hydride species. The initial stage of oxidation of silicon surface involves oxygen insertion into the silicon back bonds. The low intense peak around $979 \mathrm{~cm}^{-1}$ is due to the scissoring mode of oxygen inserted $\mathrm{Si}-\mathrm{H}_{2}$ species and indicates the presence of $\mathrm{H}_{2} \mathrm{Si}(\mathrm{O})_{x}$ type species with $x=0 \sim 2$ oxygen atoms inserted into Si back bonds (Ranga Rao et al 2004; Wang et al 2004).

The reactivity pattern of water with H-covered $\mathrm{Si}(100)$ $(2 \times 1)$ surface is shown in figure 1b. Even at high exposure of water, the surface does not show the presence of $\mathrm{H}-\mathrm{Si}-\mathrm{Si}-\mathrm{OH}$ species indicating a change in the reactivity of hydrogen covered silicon surface with water. The infrared peaks are seen at 900,913,961, 2100 and $2142 \mathrm{~cm}^{-1}$. The negative infrared absorption peak at $2100 \mathrm{~cm}^{-1}$ is due to the $\mathrm{Si}-\mathrm{H}$ stretch of the surface hydride phase (coupled monohydride species) of $\mathrm{Si}(100)-(2 \times 1)-\mathrm{H}$, the surface infrared signal of which was taken as a background. The infrared peaks at 900 and $913 \mathrm{~cm}^{-1}$ are attributed to the scissoring modes of isolated and adjacent $\mathrm{SiH}_{2}$ species. The formation of dihydrides and oxygen inserted dihydride species from coupled monohydride in the presence of water seem to occur by oxygen insertion and migration through silicon back bonds (Weldon et al 2000). The smaller intensity peak at $961 \mathrm{~cm}^{-1}$ indicates the nucleation of highly oxidized species of the type $\mathrm{H}_{2} \mathrm{Si}(\mathrm{O})_{x}$ which has the $\mathrm{Si}-\mathrm{H}$ stretching signature around $2142 \mathrm{~cm}^{-1}$. This type of species are also present to a lesser extent on water exposed $\mathrm{Si}(100)-(2 \times 1)$ surface in spectrum $1(\mathrm{a})$. It is clear that water adsorption at low exposures on clean $\mathrm{Si}(100)-(2 \times 1)$ surface produces dissociated fragments $\mathrm{H}$ and $\mathrm{OH}$ attached to silicon atoms while hydrogenated silicon $(2 \times 1)$ surface seems to favour the formation of dihydride species.

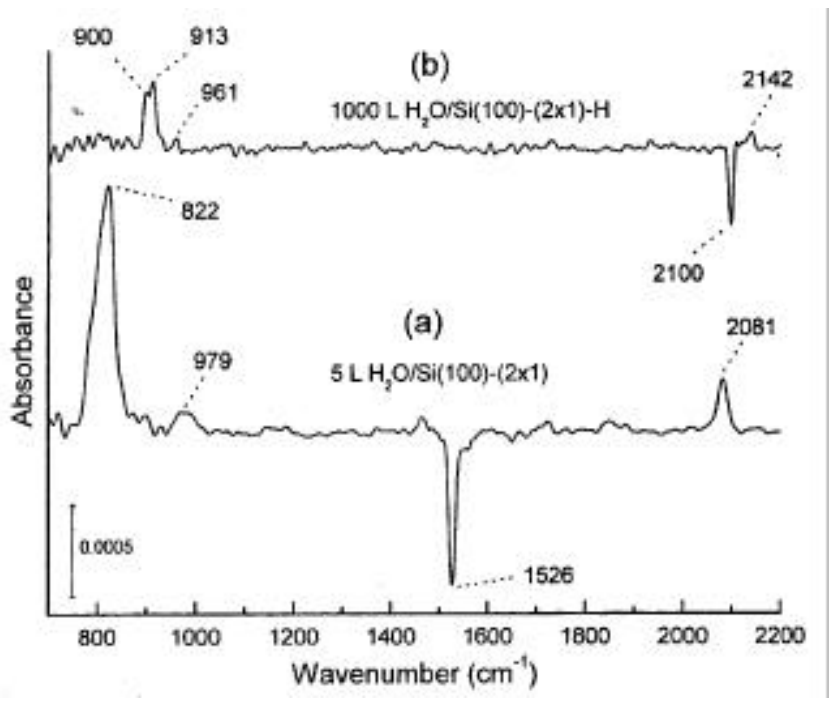

Figure 1. Infrared reflection absorption spectra of water exposed (a) $\operatorname{Si}(100)-(2 \times 1)$ and (b) $\operatorname{Si}(100)-(2 \times 1)-H$ surfaces at $373 \mathrm{~K}$.
Water adsorption is further studied on hydrogen terminated $\operatorname{Si}(100)-(3 \times 1)$ and $\operatorname{Si}(100)-(1 \times 1)$ surfaces. The $\mathrm{Si}(100)-(3 \times 1)-\mathrm{H}$ and $\mathrm{Si}(100)-(1 \times 1)-\mathrm{H}$ surfaces are obtained by saturating clean $\mathrm{Si}(100)-(2 \times 1)$ surface with atomic deuterium at $648 \mathrm{~K}$ and replacing it by atomic hydrogen, respectively, at $400 \mathrm{~K}$ and $300 \mathrm{~K}$. The infrared spectra of $5000 \mathrm{~L}$ water dosed silicon surfaces are shown in figure 2 . The infrared spectra are presented as the ratios of the absorption spectra of water exposed $\mathrm{Si}(100)-(3 \times 1)-\mathrm{H}$ surface to the $\mathrm{Si}(100)-(3 \times 1)-\mathrm{H}$ surface (spectrum $2(\mathrm{a}))$, and the water exposed $\mathrm{Si}(100)-(1 \times 1)-\mathrm{H}$ surface to the Si $(100)-(1 \times 1)-\mathrm{H}$ surface (spectrum $2(b))$. The spectrum 2(a) shows a number of infrared absorption peaks at 845 , 902, 914, 966, 981, 2100 and an intense broad band at $1000-1150 \mathrm{~cm}^{-1}$. These infrared peaks also appear in spectrum 2(b) along with new peaks at 863 and $2140 \mathrm{~cm}^{-1}$. The negative absorption peaks in spectrum 2(a) at 902 and $914 \mathrm{~cm}^{-1}$ are due to isolated and adjacent $\mathrm{SiH}_{2}$ species and the $2100 \mathrm{~cm}^{-1}$ is from coupled monohydride species present on the $\mathrm{Si}(100)-(3 \times 1)-\mathrm{H}$ surface which is taken as a background. The remaining vibrational peaks at 845,966 , 981 are assigned to oxygen inserted coupled monohydride, isolated and adjacent dihydride species, respectively (table 1). The unresolved broad vibrational feature at $1000-1150 \mathrm{~cm}^{-1}$ is related to collective $\mathrm{Si}-\mathrm{O}-\mathrm{Si}$ stretching vibrations observed on silicon surfaces containing variety of oxygen inserted silicon dimers and bulk oxides (Mawhinney et al 1997; Weldon et al 2000; Ranga Rao et al 2004).

The $\mathrm{Si}(100)-(1 \times 1)-\mathrm{H}$ surface shows similar reactivity pattern as that of $\mathrm{Si}(100)-(3 \times 1)-\mathrm{H}$ surface with water. The spectrum 2(b) shows infrared absorption peaks at $845,863,902,914,966,981,2100,2140$ and the broad vibrational feature at $1000-1150 \mathrm{~cm}^{-1}$. The negative peaks

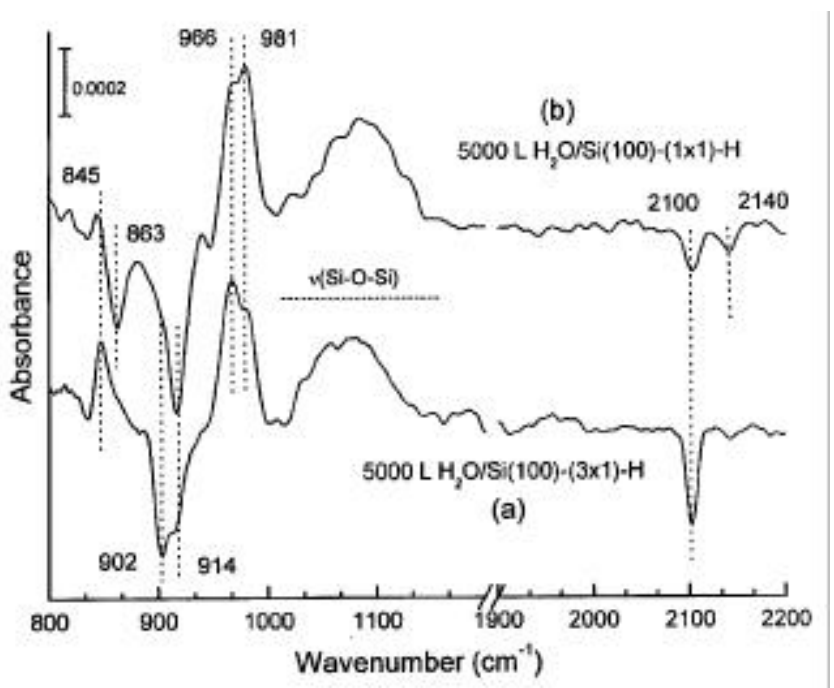

Figure 2. Infrared reflection absorption spectra of water exposed (a) $\mathrm{Si}(100)-(3 \times 1)-\mathrm{H}$ surface at $400 \mathrm{~K}$ and (b) $\mathrm{Si}(100)$ $(1 \times 1)-\mathrm{H}$ surface at $300 \mathrm{~K}$. 
Table 1. The surface species and their vibrational frequencies measured on different $\mathrm{Si}(100)$ surfaces by infrared reflection absorption method.

\begin{tabular}{llc}
\hline Species & $\begin{array}{c}\text { Vibrational } \\
\text { mode }\end{array}$ & $\begin{array}{c}\text { Frequency } \\
\left(\mathrm{cm}^{-1}\right)\end{array}$ \\
\hline $\mathrm{H}-\mathrm{Si}-\mathrm{Si}-\mathrm{OH}$ & $v(\mathrm{Si}-\mathrm{OH})$ & 822 \\
& $v(\mathrm{Si}-\mathrm{H})$ & 2081 \\
& $v(\mathrm{Si}-\mathrm{D})$ & 1526 \\
$\mathrm{H}-\mathrm{Si}-\mathrm{H}$ & $\delta(\mathrm{Si}-\mathrm{H})_{\mathrm{ID}}$ & $900-902$ \\
$\mathrm{H}-\mathrm{Si}(\mathrm{O})_{2}-\mathrm{H}$ & $\delta(\mathrm{Si}-\mathrm{H})_{\mathrm{ID}}$ & $961-966$ \\
$\mathrm{H}_{2} \mathrm{Si} \ldots . \mathrm{SiH} \mathrm{H}_{2}$ & $\delta(\mathrm{Si}-\mathrm{H})_{\mathrm{AD}}$ & $913-914$ \\
$\mathrm{H}_{2} \mathrm{Si}(\mathrm{O})_{2} \ldots \mathrm{Si}(\mathrm{O})_{x} \mathrm{H}_{2}, x=0-2$ & $\delta(\mathrm{Si}-\mathrm{H})_{\mathrm{AD}}$ & $979-981$ \\
$\mathrm{H}_{-}-\mathrm{Si}-\mathrm{Si}-\mathrm{H}$ & $v(\mathrm{Si}-\mathrm{H})_{\mathrm{CM}}$ & 2100 \\
$\mathrm{H}-\mathrm{Si}(\mathrm{O})_{2}-\mathrm{Si}(\mathrm{O})_{x}-\mathrm{H}, x=1,2$ & $v(\mathrm{Si}-\mathrm{H})_{\mathrm{CM}}$ & 2142 \\
$\mathrm{H}-\mathrm{Si}(\mathrm{O})_{2}-\mathrm{O}-\mathrm{Si}-\mathrm{H}$ & $\delta(\mathrm{Si}-\mathrm{H})_{\mathrm{CM}}$ & 845 \\
$\mathrm{SiH} \mathrm{H}_{3}$ & $\delta(\mathrm{Si}-\mathrm{H})$ & 863 \\
$\mathrm{SiH}{ }_{3}$ & $v(\mathrm{Si}-\mathrm{H})$ & 2140 \\
\hline
\end{tabular}

observed in the bending/scissoring region at 863, 902 and $914 \mathrm{~cm}^{-1}$ show the presence of $\mathrm{SiH}_{3}$, isolated and adjacent $\mathrm{SiH}_{2}$ species, respectively. In the $\mathrm{Si}-\mathrm{H}$ stretching region, the peaks at 2100 and $2140 \mathrm{~cm}^{-1}$ are the signatures of the couple monohydride and $\mathrm{SiH}_{3}$ species, respectively (Noda and Urisu 2000). These characteristic $\mathrm{Si}-\mathrm{H}$ bending and stretching modes confirm the $(1 \times 1)-\mathrm{H}$ surface as a starting point. Water adsorption on this surface gives positive peaks at 845,966 and $981 \mathrm{~cm}^{-1}$ and the broad vibrational structure at $1000-1150 \mathrm{~cm}^{-1}$ which are similar to those observed on $\mathrm{Si}(100)-(3 \times 1)-\mathrm{H}$ surface (table 1$)$. These results show that clean $\mathrm{Si}(100)$ surface is more sensitive to water chemisorption than $\mathrm{H}$-terminated $\mathrm{Si}$ surfaces. At low exposures bare $\mathrm{Si}(100)-(2 \times 1)$ surface dissociates water molecule. The hydrogen reconstructed silicon surfaces tend to produce surface oxygenated dihydrides which show blue shifts in the $\delta(\mathrm{Si}-\mathrm{H})$ vibrational frequencies.

\section{Conclusions}

Water adsorption is dissociative on $\mathrm{Si}(100)-(2 \times 1)$ surface giving rise to $\mathrm{H}-\mathrm{Si}-\mathrm{Si}-\mathrm{OH}$ species. The hydrogenated $\mathrm{Si}(100)$ surfaces tend to produce dihydride and oxygenated dihydride species at larger water exposures.

\section{Acknowledgements}

The author would like to thank Professor Urisu and Dr Wang for experimental help and several insightful discussions at IMS.

\section{References}

Ashkenasy G, Cahen D, Cohen R, Shanzer A and Vilan A 2002 Acc. Chem. Res. 35121

Bitzera T, Richardson N V and Schiffrin D J 1997 Surf. Sci. 382 L686

Buriak J M 2002 Chem. Rev. 1021271

Chabal Y J and Raghavachari K 2002 Surf. Sci. 502-503 41

Ehrley E, Butz R and Mantl S 1991 Surf. Sci. 248193

Gurevich A B, Stefanov B B, Weldon M K, Chabal Y J and Raghavachari K 1998 Phys. Rev. $B 58$ R13434

Hamers R J, Hovis J S, Coulter S K, Ellison M D and Padowitz D F 2000 Jpn. J. Appl. Phys. 394366

Ibach H, Wagner H and Bruchmann D 1982 Solid State Commun. 42457

Ikeda H, Hotta K, Yamada T, Zaima S and Yasuda Y 1995 Jpn. J. Appl. Phys. 342191

Jones L A, Taylor G M, Wei F X and Thomas D F 1995 Prog. Surf. Sci. $\mathbf{5 0} 283$

Kobayashi Y, Sumitomo K, Prabhakaran K and Ogino T 1996 J. Vac. Sci. Technol. A14 2263

Liu W K, Mokler S M, Ohtani N, Roberts C and Joyce B A 1992 Surf. Sci. 264301

Mawhinney D B, Glass Jr. J A and Yates Jr. J T 1997 J. Phys. Chem. B101 1202

Noda H and Urisu T 2000 Chem. Phys. Lett. 326163

Ogata Y, Niki H, Sakka T and Iwasaki M 1995 J. Electrochem. Soc. 1421595

Ranga Rao G, Wang Z H, Watanabe H, Aoyagi M and Urisu T 2004 Surf. Sci. 570178

Reddy R R K, Chadha A and Bhattacharya E 2001 Biosensors Bioelectronics 16313

Struck L M et al 1997 Surf. Sci. 380444

Tautz F S and Schaefer J A 1998 J. Appl. Phys. 846636

Waltenburg H N and Yates Jr. J T 1995 Chem. Rev. 951589

Wang Z H, Noda H, Nonogaki Y, Yabumoto N and Urisu T 2002 Jpn. J. Appl. Phys. 414275

Wang Z H, Urisu T, Nanbu S, Maki J, Ranga Rao G, Aoyagi M, Watanabe H and Ooi K 2004 Phys. Rev. B69 45309

Weldon M K, Stefanov B B, Raghavachari K and Chabal Y J 1997 Phys. Rev. Lett. 792851

Weldon M K, Queeney K T, Gurevich A B, Stefanov B B, Chabal Y J and Raghavachari K 2000 J. Chem. Phys. 1132440 